up this system, but eliminating the group with " ease and certainty" has no precise meaning.

I. M. Heillbron.

R. A. Morton.

Department of Chemistry,

University, Liverpool, May 26.

1 Bowden and Snow, NATURE, 129, 720, May 14, 1932

2 Morton and Heilbron, Biochem. J., 22, 987; 1928.

${ }^{8}$ Rygh and Rygh, Z. physiol. Chem., 204, 114; 1932.

- Zilva, J. Soc. Chem. Ind., 51, 166; 1932.

5 Dulière, Morton, and Drummond, J. Soc. Chem. Ind., 48, $316 \mathrm{~T}$; 1928

Karrer, Morf, and Schöpp, Helv.

7 Heilbron, Heslop, Morton, Drummond, and Rea, J. Soc Chem. Ind., 51, 164. 1939.

Moore, Biochem. J., 23, 803 ; 1929.

- Gillam, Morton, Heilbron, and Drummond, J. Soc. Chem. Ind., 51,$164 ; 1932$.

10 Windaus, Proc. Roy. Soc., B, 108, 568; 1931

\section{Resistance of the Eggs of Collembola to Drought Conditions}

THE activity and abundance of Collembola are closely associated with the moisture of their environment. The species Sminthurus viridis (L.) Lubb. occurs in large numbers in certain areas of South Australia during the rainy season (May to October). The numbers rapidly decrease when the dry season sets in and, normally, the insect does not occur again until about the following May.

Certain of the eggs remain dormant in the soil during the dry season. This condition is not due to a definite rhythmical diapause, but is enforced owing to the lack of moisture in the surface soil during this

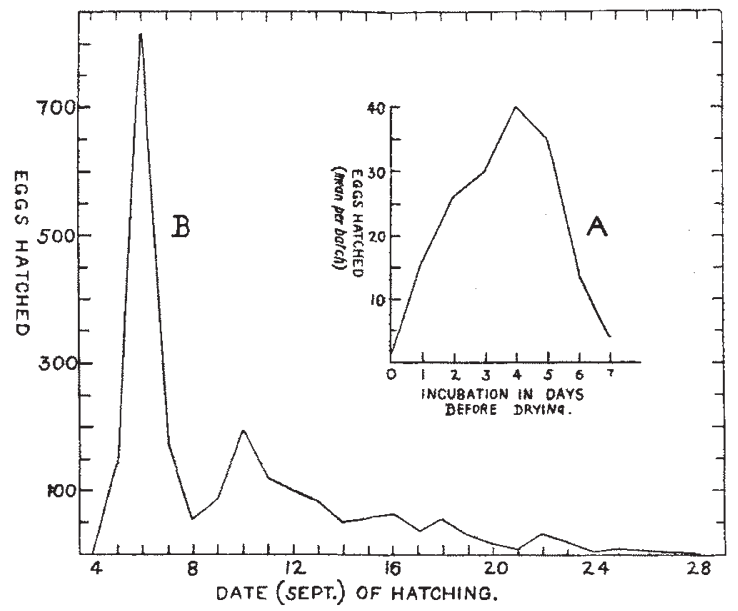

FIG. 1.

season. The eggs can be induced to hatch with suitable moisture and temperature.

During experimental work with this species, it was found that with egg batches, exposed to dry conditions for varying periods and then remoistened, the eggs commenced to hatch in a comparatively short time, showing that some development had taken place prior to being remoistened.

The stage of development attained by the eggs prior to the onset of dry conditions is an important factor affecting the number which survive a temporary drought period. 100 egg batches of S. viridis, estimated at 4500 eggs, were arranged in eight series (Series 7 to 0 ). The number of batches in each series was $18,13,14,13,14,9,8,11$. The batches were laid on moist soil contained in $2 \frac{1}{2}$-in. flower pots, the conditions being uniform. There were six pots in each series, and the batches were retained, as laid, in situ on the soil, throughout the experiment.

With Series 7 , the pots were placed in an incubator at $24^{\circ} \mathrm{C}$. for 7 days from the date of being laid, the soil being kept suitably moist. With Series 6, the pots were 6 days in the incubator, and so on, with the remaining series to Series 0 with no days in the incubator. All the pots were then transferred to a heated glass-house on the same day (Aug. 15) and the soil allowed to dry out for 17 days. (Mean daily max. temp. $30^{\circ}$ C., min. temp. $12^{\circ} \mathrm{C}$. Mean daily relative humidity 56 per cent.) By Aug. 17 the moisture content of the surface soil, based on the moist soil, was 2.5 per cent. On Sept. 1 , the soil in all the pots was remoistened and the daily hatching from each series was recorded. (During the period, Sept. 1-16, the mean daily max. temp. was $28^{\circ} \mathrm{C}$, and mean min. temp. $11^{\circ} \mathrm{C}$.)

A total of $2144 \mathrm{eggs}$ hatched. The mean number of eggs per batch which hatched in each series is shown in Fig. 1, $A$, and the daily total of eggs which hatched from all the series is shown in Fig. 1, $B$. (In Series 7 , 93 eggs hatched during Aug. 17-20. In Series 6, 86 eggs hatched during Aug. 18-20. These are not included.) I have discussed the normal incubation period elsewhere. ${ }^{1}$

The relative resistance of the egg at different stages appears to be associated with the changes occurring during development. In the advanced stages of the embryo, the egg swells and the chorion splits at the equator. Two polar caps are thus formed which gradually separate, revealing the embryo surrounded by a transparent membranous envelope.

Ripper ${ }^{2}$ has described changes in the egg of Hypogastrura in this respect, which differ in detail from that of $S$. viridis.

The Waite Institute,

University of Adelaide, March 31.

Australian J. Expt. Biol. and Med. Science, 8, 143 ; 1931.

Z. angew. Entom., 16, 559; 1930.

\section{Inheritance of Milking Capacity}

IN replying to Mr. Buchanan Smith's remarks ${ }^{1}$ con. cerning my discussion ${ }^{2}$ of Mr. Madsen's letter, ${ }^{3}$ I shall deal with them in the order set out by him.

(1) I suggested that the small correlation to the paternal granddam might be explained by the selection of the sires of bulls studied as prepotent on the basis of the progeny test (rather than on their dams' records), a form of reasoning used by Mr. Buchanan Smith for another purpose ${ }^{4}$ in discussing a low correlation of daughters' yields to their paternal granddams' yields when he states ". . . this . . may probably be explained by the fact that up till quite recently in the Ayrshire breed the bull was selected not on the performance of his dam so much as on the showyard record of his sire ". In each case the principle is obviously the same-the bull being selected with little reference to his dam's record. Mr. Buchanan Smith's statement that "when the full paper is published Mr. Madsen will show that the majority of sires involved have not been selected on genotype but on appearance plus pedigree " is difficult to reconcile with Mr. Madsen's own statement about "... breeders who for the past 15 years have, through an intelligent appreciation of the progeny test, paid almost exclusive attention to the male line",

(2) Rather than to the contrary we find ourselves in agreement on the second point ; I stated that a cow's record is insufficient in foretelling the production 